\title{
Erratum to: Who Should Be Considered for Islet Transplantation Alone?
}

\author{
Nantia Othonos ${ }^{1} \cdot$ Pratik Choudhary $^{1}$
}

Published online: 29 March 2017

(C) Springer Science+Business Media New York 2017

Erratum to: Curr Diab Rep (2017) 17: 23

DOI 10.1007/s11892-017-0847-6

The original version of this article contained an error in the abstract in the following sentence. "Results from studies of islet transplantation suggest the optimal recipient characteristics for successful islet transplantation include age $>35$ years, insulin requirements $<1.0 / \mathrm{kg}$, and weight $>85 \mathrm{~kg}$." It should be weight $<85 \mathrm{~kg}$ instead.

The online version of the original article can be found at http://dx.doi. org/10.1007/s11892-017-0847-6

Pratik Choudhary

Pratik.choudhary@kcl.ac.uk

1 Department of Diabetes, King's College London, Denmark Hill, London SE5 9RJ, UK 